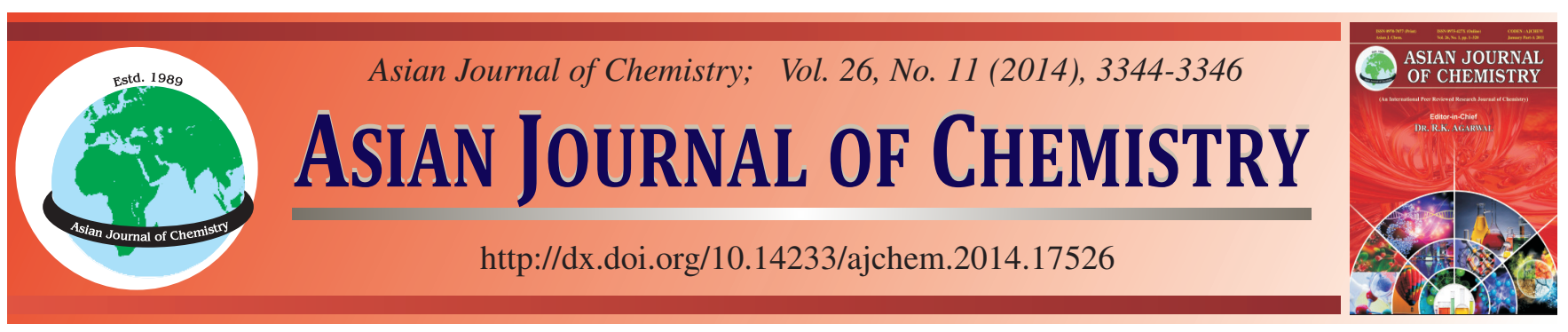

\title{
Interpretation of Green, Environmentally Friendly and Energy-Conserving Design of Water Cube, PTW National Swimming Centre
}

\author{
ZhaOyuan Huang ${ }^{1,2, *}$ and Mixue $\mathrm{He}^{1}$
}

${ }^{1}$ Institute of Physical Education, Liaoning Normal University, Dalian 116029, Liaoning Province, P.R. China

${ }^{2}$ Institute of Physical Education, Changchun Normal University, Changchun 130032, Jilin Province, P.R. China

*Corresponding author: Fax: +86 431 86168196; Tel: +86 431 86168070; E-mail: hzy1353160@ sina.com

Received: 12 February 2014;

Accepted: 15 April 2014;

Published online: 25 May 2014;

AJC-15245

\begin{abstract}
The complicated and free structural form of the PTW National Swimming Centre, which was the venue of the 2008 Beijing Olympic Games, originates from the delicate and simple variation of the planned system. It is a new building miracle, which integrates the latest research results of green, eco-friendly and energy conserving buildings in the green swimming pool and is designed based on the green and eco-friendly building standards in full consideration of energy conservation, use of environmentally friendly materials and protection of water resources. The PTW National Swimming Centre is a typical environmentally-friendly and energy-conserving building. It pioneers the systematic energy-conserving and environmentally-friendly building of China in the field of promoting and marketing eco-friendly and energy conserving buildings and it is very meaningful. In this paper, the technical design of the PTW National Swimming Centre in terms of water conservation and environmental protection is analyzed and interpreted deeply to facilitate the promotion of environmental protection technology.
\end{abstract}

Keywords: PTW National swimming centre, Green and environmentally friendly, Energy conservation, Utilization.

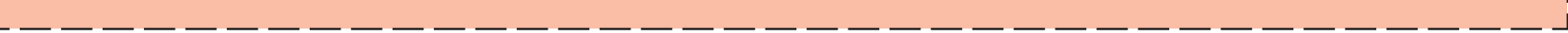

\section{INTRODUCTION}

The PTW National Swimming Centre is located in Beijing Olympic Park and is one of the landmark buildings of the 2008 Beijing Olympic Games covering 100 thousand square meters in total. The PTW National Swimming Centre is built, managed and operated by Beijing State-owned Assets Management Co, Ltd. and its construction started on December 24, 2003 and was completed in January, 2008.

The water cube is a building with water. Water is the soul of this building and the entire building is around the theme of "water", the dreamy blue swimming pool looks like a glittering water drop in the sun and inside, it looks like a sea. However, a 1 eot of water is consumed every day herein and the comprehensive utilization of the water resource is an important problem to be solved for the PTW National Swimming Centre ${ }^{1}$ (Fig. 1). A lot of measures have been taken to reduce the water consumption and waste water drainage. Over a year, more than ten thousand tons of rainwater, seventy thousand tons of waste water from bathing and sixty thousand tons of swimming pool water is collected. The water used for afforestation, filling water into the cooling tower and moating, flushing toilet and washing the ground comes from the recycled water and in this way,

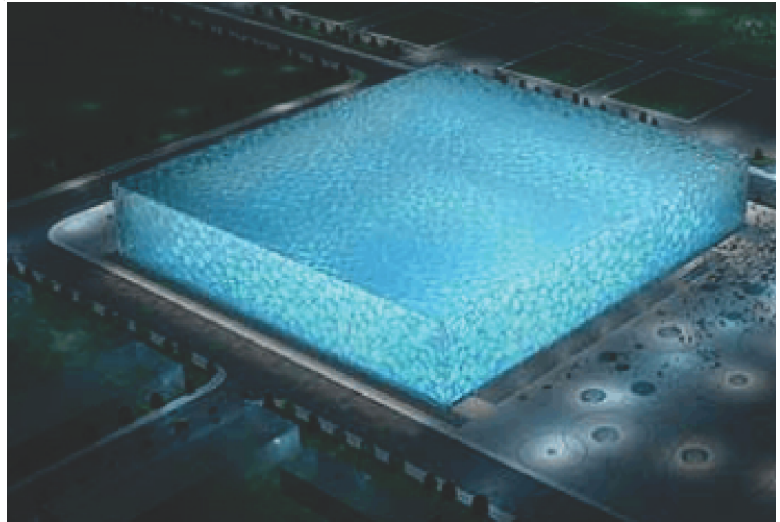

Fig. 1. Outside scene of the PTW National Swimming Centre

the waste water drained is reduced by 140 thousand tons every year.

Humanized design of the water cube: The swimming pool in the PTW National Swimming Centre is as deep as 13 meters so as to reduce the interference with the sportsmen arising from the water temperature. When it is used, the water temperature of the swimming pool is $28^{\circ} \mathrm{C}$, which is the best for the sportsmen to call their potential into full play ${ }^{2}$. 
The indoor environment of the PTW National Swimming Centre is designed in full consideration of the demands of both the sportsmen and the audience. For instance, illuminating equipment is installed at an optimized angle to not only remove the influence of light on the sportsmen, but also provide a desirable environment for the audience to watch the games.

The audience's demands are fully considered while the indoor environment of the water cube is designed and large screens up to 23.8 square meters are installed on both sides of the swimming pool.

The sportsmen will not feel cold while walking on bare feet. As there is a distance between the swimming pool and the warm-up pool, the sportsmen have to move between the two pools on bare feet. The floor between is specially and carefully treated and the sportsmen will feel comfortable and will not feel cold when walking on the floor ${ }^{3}$.

A lot of innovative designs are applied on the swimming pools in the Swimming Centre, such as bringing the air on the surface of the swimming pool from outdoors, porous terminal bank and transmitting visual and audio signals and so on. Some high technology equipment is introduced, such as optical devices to locate the sportsmen, multi-angle three-dimensional image projection system and so on which will help the audience to watch the games better.

\section{Use of the green, environmentally-friendly and energy} conserving measures on the water cube

Function of self-cleaning and water collection: Another one of the most innovative features of the Water Cube is its water treatment system. Most of the swimming pools directly drain the water from swimming and bathing into the city's sewerage system, but PTW National Swimming Centre may treat and recycle the water with just a small portion of waste water lost during the treatment, which will be replaced with the rainwater collected on roof ${ }^{4}$. The membrane ETFE used for the PTW National Swimming Centre not only is environmentally friendly, energy conserving, but also may clean itself (Fig. 2). ETFE membranes are not hydrophilic, namely, no water is left when running across the membranes and the sundries, dust and soil and so on on the air pillow will be cleaned by natural rainwater. The National Swimming Centre has prepared a complete cleaning solution used for cleaning the wall and the roof. Not only rain water is used for cleaning itself, a rain recycling system is designed specially for this. 80 $\%$ of the water consumed by this centre will be recycled from the roof, thus reducing our reliance on the water supply and the waste water drained into the sewage. The double filters in the swimming pools can recycle water and even excess rainwater is collected and stored in the underground water tanks. The quantity of water recycled one year is about 10500 cubic meters and the total water collected about 29000 cubic meters, $76 \%$ of rainwater is utilized, which is about the yearly water consumption by 100 households 5 .

The water quality in the swimming pools is designed based on the current FINA standard. During normal circulation of water, the overflowing water from the swimming pool will return to the equalizing tank through the overflowing channels around and the water passes through the hair collector to remove the hair and big particles and then are pressurized by the

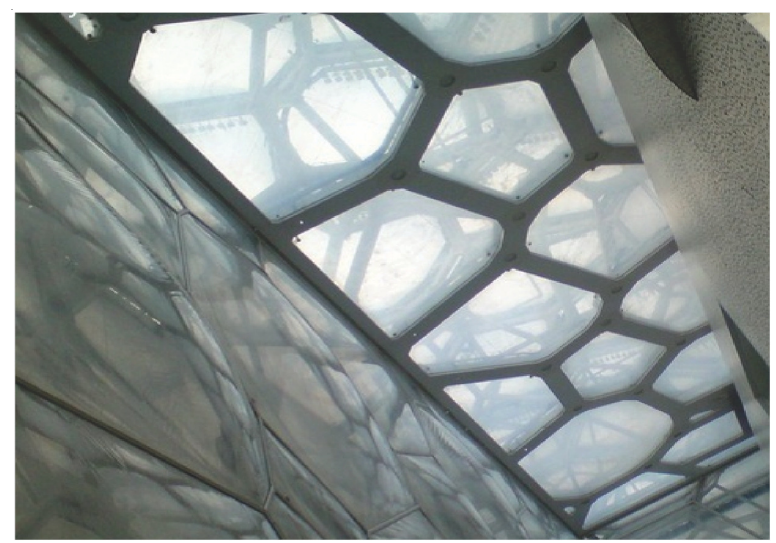

Fig. 2. Indoor natural lighting effect inside the water cube by using the ETFE membranes

circulating pump and then fully reacts with coagulant added, the mixture enters the silica-sand filter to remove the suspended substance and colour. The filtered water is ozonated for sterilization and then enter an active carbon tank, then filtered and then enter a heat exchange unit and then is split and heated; the water having passed through plate heat exchanger and the water that is not heated are fully mixed; temperature monitoring points are set at the water collecting pipes for regulating the quantity of heat media, thus controlling the water temperature.

In case of rainy weather, the water on the roof will be collected and is split, stored, filtered, sterilized and then is recycled. The rainwater treated is recycled for the water scenes and the cooling towers depending on the rainy season features and water quality features. Averagely, 10,500 cubic meters of rain water may be recycled every year and the rainwater collection area on the roof covers about 29 thousand square meters with the rainwater utilization ratio of about $76 \%$ and 10475 cubic meters of rain water may be provided every year ${ }^{6}$.

A reclaimed water system is established at the National Swimming Centre and a DN80 ordinary reclaimed water inlet pipe is set from the scenery road for feeding water in case of insufficient reclaimed water in the self-built reclaimed water stations and failure to run. The self-built reclaimed water station teats reclaimed water at the rate of $220 \mathrm{~m}^{3} / \mathrm{d}$ and may run continuously, as well as adopt the membrane bio-processing technology ${ }^{7}$.

Natural light used for power conservation: In order to reduce the carbon dioxide generated, power utilization is reduced in design. Solar cells are used to provide power. In most cases during games, the lights are off, unlike the open swimming pools that were mostly used in previous Olympic Games, the Water Cube adopts the totally enclosed design. As the ETFE membrane roof is used, $90 \%$ of natural light may enter the stadium and for nearly $10 \mathrm{~h} /$ day, natural light can be used; and no lamps are on in most cases during the games. Novel materials are used on the floor to reduce the air conditioner load and lighting load by $20-30 \%$. The system also recovers waste heat and the application of the heat recovery freezer saves the power by 600 thousand kilowatt hours per year. All these measures significantly reduce the energy resource consumption.

Reflection and temperature regulation with the coating points on the membrane: The water cube is a semi-transparent 
building and is designed to absorb natural light with the membrane structure to regulate the light and temperature inside to achieve the objective of energy conservation and environmental protection. However, just by virtue of the smooth membrane, it is troublesome to turn it into a green house, let alone regulating the light and the temperature. The round coating points are the secrets to solve this problem. They are like small sunshades and play roles in isolating and reflecting light and block the dazzling light and excess heat outside (Fig. 3). In the north, the sunlight load is small, for this reason, the density of the coating points is small and the northern space feels clear. However, in the west and east, as the incoming sunlight is intense and the coating points are denser. In order to keep the indoor environment cool when the sunlight is intense or it is exposed to the intensive heat of the afternoon sun, the small sunshades must be distributed accurately.

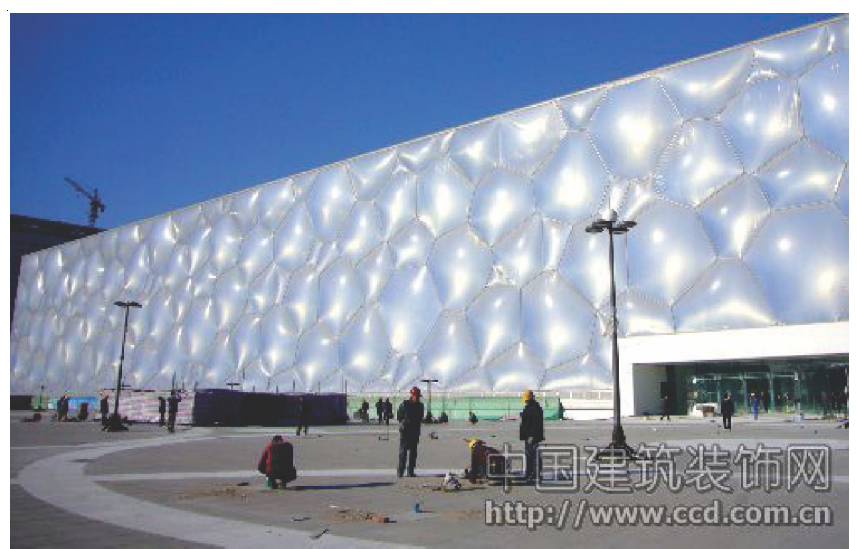

Fig. 3. Outdoor isolation and light reflection effect with ETFE membrane

Researchers determine the areas of the coating points required on every membrane based on the last 30 years' Beijing climate data by precise calculation. On the main part of the southern elevation, the area covered by the coating points is less than $50 \%$; on the western elevation, the coating points covers $60 \%$ of the total area. By arrangement of the coating points in this way, the western elevation may block more than $70 \%$ of solar energy from the building.
The designers have also designed a heat recovery air conditioning system to recover the waste heat and reduce the water consumption and it is a advanced technology in China. The heat recovered in winter is used for preheating the air outdoors, which is applied for games, thus saving energy by $60 \%$ and about 1260 kilowatts of heat is recovered. The highintensity discharge lights over the venue use HEPS power energy.

Energy conservation auxiliary system: By using the energy conservation auxiliary system and high quality electromagnetic rectifiers, the use efficiency of the lights is improved. It is predicted that the power consumption will be reduced by $30 \%$, namely, about 400 kilowatts and the pollution to the grid is reduced by $30 \%$; energy conservation power supply and distribution technology and equipment is used and electric systems are established based on the nature and classifications of the load; the transformer low voltage system of the main substation distribution room $3 \mathrm{~T}$ and $5 \mathrm{~T}$ covers up to $50 \%$ and the open circuit loss of the transformer is reduced by $30 \%$.

The modern Olympic Games have gone beyond what the pure competitive sports mean and have become a world-class gathering and is a comprehensive display of society, culture and technology. The water cube is a model of energy conservation and environmentally friendly building in China and it is the only comprehensive and systematic high technology building for studying and configuring energy conservation and environmentally friendly system, which gathers and contains modern scientific and technical measures. It embodies the combination of green and high technology perfectly.

\section{REFERENCES}

1. F. Zheng and X. Zhang, Building J., 6, 22 (2008).

2. M.S. Lin, Architect, 3, 12 (2008)

X.G. Li, Building Creation, 7, 45 (2007).

4. X.M. Zhang and Z.X. Zhao, Building Technol., 3, 106 (2008).

5. X.L. Li, W.M. Yun, R.C. Lin and N. Li, Electric Technol. Intelligent Buildings, 1, 120 (2008).

6. X.M. Chen, Z.X. Zhao and X. Zhang, Building Technol., 3, 87 (2008).

7. Beijing Organizing Committee of Olympic Games, Building, 9, 34 (2008).

8. F. Zheng, Building Creation, 7, 88 (2007). 